\title{
On Flexibility in Architecture Focused on the Contradiction in Designing Flexible Space and Its Design Proposition
}

\author{
Young-Ju Kim \\ Assistant Professor, Dept. of Architecture, PaiChai University, Daejeon, Korea
}

http://dx.doi.org/10.5659/AIKAR.2013.15.4.191

\begin{abstract}
Since Modern Movement flexibility has been one of the most attractive words in architecture. However, "overprovision first, division later" has been the most prevailing design method for spatial flexibility, and many of buildings designed for flexible use are practically quite inflexible due to insufficient building systems or/and irresponsible planning. There have been two dominant strategies to achieve architectural flexibility: multi-functionality and polyvalence. These two approaches, which point contradictory directions, actually reflect the difficulty in providing a proper form of architectural flexibility. Multi-functionality can afford changeable environments with satisfying spatial conditions; however it lacks tolerance to accommodate other uses but intended functions by architects. Meanwhile, flexibility by a polyvalent form relies on the vague anticipation of user's various interpretations. In this study by looking up these two different standpoints and historical precedents flexibility in architecture is carefully scrutinized focused on the contradiction, and as an alternative for architectural flexibility contextual relations is proposed. Unlike both multi-functionality and polyvalence, which produce flexibility by changing its own properties, manipulating contextual relations infuses flexibility into space by changing the properties of a building, not of its individual room. By using this contextual relations method, a community-centered school in Manhattan, NY, which was in danger of being closed because of its academic failure, is represented as a flexible space.
\end{abstract}

Keywords: Flexibility, Multi-Functionality, Polyvalence, Contextual Relations, Community-Centered School

\section{FLEXIBILITY: ARCHITECT'S FANTASY}

Since Modern Movement flexibility has been one of the most attractive words in architecture. In 1954, Walter Gropius insisted that architecture needs to be flexible enough to contain "the dynamic features of modern life." (Forty, 2000) In addition, by mentioning the obsoleteness of the contemporary society Richard Rogers called for the appropriate architectural solution. Rogers said,

The impact of accelerating change on the physical form of the city is radical. ... and it is now commonplace to anticipate that a building will outlive the purpose for which it is built in a matter of a few years. Modern life can no longer be defined in the long term and consequently cannot be contained within a static order of symbolic buildings and spaces. ... Buildings no longer symbolize a static hierarchical order; instead, they have become flexible containers for use by a dynamic society (Rogers, 1998).

Corresponding Author : Young-Ju Kim, Associate Professor

Department of Architecture, PaiChai University, Daejeon, Korea

Tel : +82-41-520-5498 e-mail : yjkim78@gmail.com

This is an Open Access article distributed under the terms of the Creative Commons Attribution Non-Commercial License (http://creativecommons. org/licenses/by-nc/3.0/) which permits unrestricted non-commercial use, distribution, and reproduction in any medium, provided the original work is properly cited.
Many of buildings designed for flexible use, however, are practically quite inflexible due to insufficient building systems or/ and irresponsible planning. In 2004, the Bellevue Art Museum in Bellevue, WA, designed by Steven Holl, was temporarily closed. The main reason was local financial difficulties, but there were also some problems with its exhibition space. The building is too sculptural for traditional art exhibition, and part of the exhibition space was left as an open space for flexible use. As for the contemporary trend toward big galleries for flexibility, Michael Auping, who is a chief curator at the Modern Art Museum in Fort Worth, Texas, said

Architects say, "I know you need big, open, flexible spaces, then you can build walls when you need them." Flexibility is a myth. When you do build walls inside these big spaces, it ends up looking like a trade show. Why not get it right from the get-go?

Is flexible space no more than an architect's fantasy who wants to control the building he or she designed even after handover? The word, "flexibility", has been too important to be simply ignored since 1950s in bringing new elements-time and the unknowninto architecture which suggests an alternative for overwhelmed Functionalism (Forty, 2000). Additionally the idea of spatial flexibility is gaining its importance engaged with sustainability and mobility which are one of the main key issues in contemporary

\footnotetext{
${ }^{1}$ Lloyd, Ann W. "If the Museum Itself Is an Artwork, What About the Art Inside?", The New York Times, 25 Jan. 2004
} 
architecture.

Above all, it should be noted that flexibility is beset by two different demands in terms of functions; one is supporting multifunctions, the other is criticizing the deterministic feature of functionalism. In this study, by looking up these two different standpoints and historical precedents flexibility in architecture is scrutinized focused on the irony, and under this contradictory situation, it might be accepted as an unpractical or somewhat a visionary proposition, a possible design proposal for flexible space will be presented.

\section{MULTI-FUNCTIONALITY}

It is obvious that the word "flexibility" is about how a space performs and how users use the space. A flexible space literally implies a multi-functional space. Unless building systems can be designed to meet the future utility demands, architectural flexibility means very little.

Here lies a common error which architects generally commit in carrying out flexible space planning. "Overprovision first, division later" has been one of the most prevailing design methods for spatial flexibility. By this method, the space is left incomplete and unfinished with waiting for users' decisions in spite of the fact that a space needs to be equipped with proper building systems such as lighting, acoustics, finishes, and structure. As Rem Koolhaas emphasized the growing role of building systems in his article "Last Apples," building systems play an important role in contemporary architecture. In a way, flexibility of building is derived from multifunctions supported by relevant building systems.

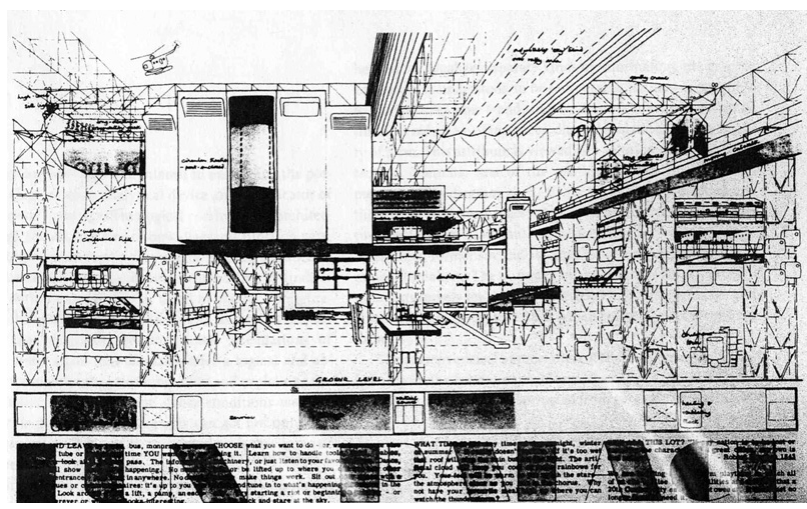

Figure 1. Fun Palace project by Cedric Price . Lobsinger, 2000, 21

In this sense, as a truly multi-functional space Cedric Price's "Fun Palace" Project(Fig.1) is worth looking at. The Fun Palace started as a proposal for a new type of performance space inspired by Joan Littlewood, who tried to establish radical theater scene. She desired a new theatrical space where her performance could be unconstrained by built form. As an architect with a penchant for technology, Price designed "an infinitely flexible, multiprogrammed, twenty-four-hour entertainment center that marries communications technologies and industrial building components to produce a machine capable of adapting to the needs of users (Goldhagen and Legault, 2000)."

Though the project started for new prototype of performance place, Fun Palace project developed in more inclusive direction, as an architectural symbol to provide intangible experience by manipulating new technology. In order to be more faithful to representing technology, Price rejected any formal approach. The Fun Palace was designed in a purely multi-functional form supported by literally moving and changing mechanical instruments and information technology.

The Fun Palace was too successful to be remained as a piece of architecture because the start of the project was anti-architectural to evoke the interaction between the space and occupants(performers and audience), which rejected determinant features in architecture. Thus Price challenged to represent architecture into another ephemeral technology rather than into traditional formalism. George Baird argued that Price's refusal to provide "visually recognizable symbols of identity, place and activity" and his reduction of architecture to a machine for "life-conditioning" displayed a gross misconception of architecture's place in human experience. (Goldhagen and Legault, 2000) Though the fact that the Fun Palace was a good example to achieve pragmatic flexibility by utilizing technology, it is too radical to be practically remained as a building to contain daily-life.

While Fun Palace pursues flexibility through moving building components, there are some precedents to achieve flexibility by interchangeable units based on modular planning.
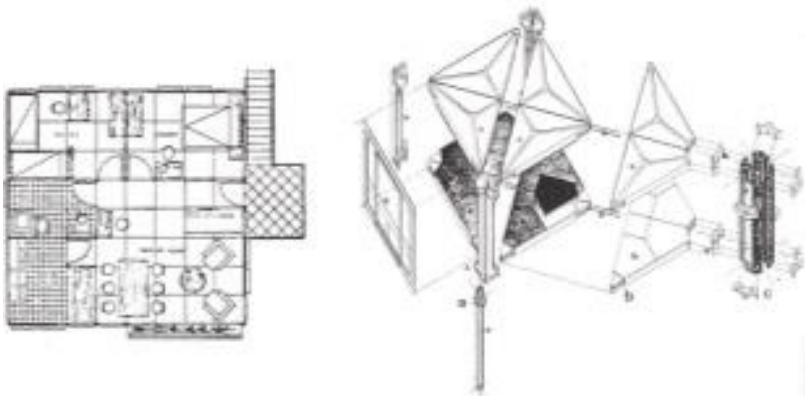

Figure 2. Meudon house (Left), Rabeneck and al., 1973, 703 Figure 3. S.I.R.H. system (Right), Rabeneck and al., 1973, 703

Jean Prouvé designed several projects in which the plan is intended modifiable. Meudon house(Fig.2) was designed for the government competition in 1938, and a hundred of $8 \mathrm{~m}$ by $8 \mathrm{~m}$ houses were ordered for housing on airfields after the war. This house is planned in $1 \mathrm{~m}$ module with all panels interchangeable. Every panel is light enough for one man to carry. The houses were produced very quickly and assembled in a day by four men. Materials are steel, aluminum, and timber. Exterior wall unit can be selected by occupant's choice among solid, window, door, etc. The same rule of choice is applied to the interior space as well. In addition, Prouvés interest in the manufacturing and assembly developed a modular construction system called S.I.R.H.(Fig.3). This system is fully industrialized using eight basic components. Though Jean Prouvé did not put the idea of flexibility to the forefront by this project, this kind of industrialized construction system gave some clue for architectural flexibility hereafter.

The Espace construit adaptable(Fig.4) by Bernard Kohn and Georges Maurios was built at Val d'Yerres in France. Based on occupant's participation, within the modular construction system occupants can choose their living kits, which is interchangeable, such as bathroom, kitchen, balcony, and partitions from a catalogue to put in their flat. The role of architect is to help them to choose the right kit for their intention or life style within their budget. 

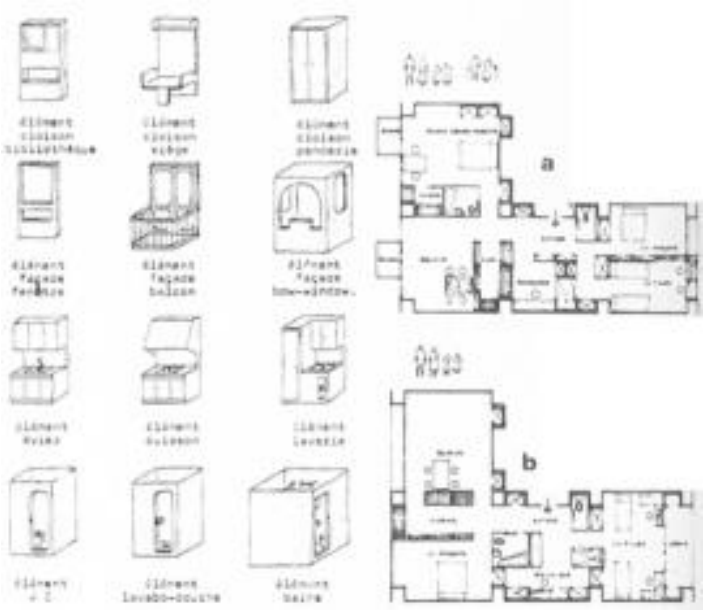

Figure 4. Espace construit adaptable. Rabeneck and al., 1973, 707

In this housing it is remarkable that the layout of the flat is fully customized to occupants' demands, which is quite flexible to occupants' situations like the number of family and their budget by choosing and replacing the interchangeable living kits.

Thus far some precedents showing multi-functional flexibility are enumerated. Multi-functional flexibility is achieved by literally changing spatial properties-such as size, lighting and acoustic conditions or by replacing the space itself. This physical change of space enables space to be highly responsive to users demands with satisfying given environmental requirements. However, in general, once a building design completed, one or two years is necessary to build it, and the building will be occupied at least for two or three decades. The multi-functionality derived from anticipated functions designated by architect fixes the space only for some uses during design stage which is too early considering the building's life span. This is the irony of multi-functionality which many architects pointed out including Henri Lefebvre, who criticized the pitfall of functionality in the sense of flexibility in that deterministic excess of functionalism might eliminate "the very possibility of multifunctionality." (Lefevre, 1991)

At this point we may need to look up flexibility in a different point of view apart from the conception of "function."

\section{POLYVALENCE}

In the article, "Functionality, Flexibility And Polyvalence," Herman Herzberger warned that the direct application of all specific functions into a space results in the fragmentation of the space rather than the integration. In his view, flexibility is the "polyvalence of a space." Aldo Rossi is another figure who appreciated the adaptability of traditional urban form by criticizing the modern architecture in the name of "naïve functionalism." Rossi proposed that traditional urban forms are more resilient, more flexible than the modern architectures that were designed by empiricism and revealed that the naive functionalism is not enough to express or explain the very complicated urban phenomena such as adaptable urban structures and viable social lives. Hertzberger and Rossi stressed flexibility derived from an archetypical form. This kind of typical forms can be categorized as following.
1) Centripetal type

Andrew Rabeneck, David Sheppard and Peter Town showed that many housing forms have been designed to be appropriate as adaptable space in the article "Flexibility/Adaptability". The historical forms as models of adaptability they inferred are: a) The Mediterranean and Mesopotamian courtyard houses, in which the open courtyard functions as a multi-purpose space(Fig.5), b)the intersection of the Palladio's villas surrounded by hierarchically arranged rooms(Fig.6), c)some of the work of Beherens, Loos, and Baillie-Scott(Fig.7,8) and d)some of European housing works in the post war period.(Rabeneck and al., 1974) Every type they inferred has a central space without fixed functions. Its layout is designed to allow as wide a range of interpretations as possible. Minimum predetermination results in ambiguity for freedom of occupants choice. This type of space is the most widely used as a flexible space through the human history. However the variety of allowable activities in this central open space is limited, which can explain why this type of flexibility may work better in private house or flats rather than in any public buildings.

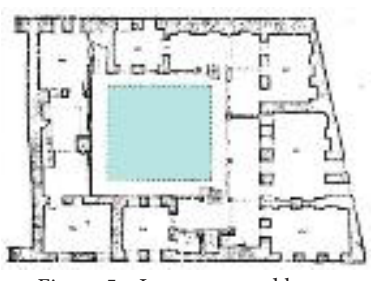

Figure 5. Irag courtyard house

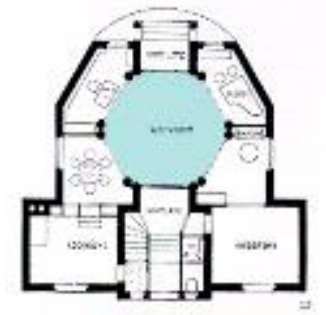

Figure 7. Summer villa, Peter Behrens

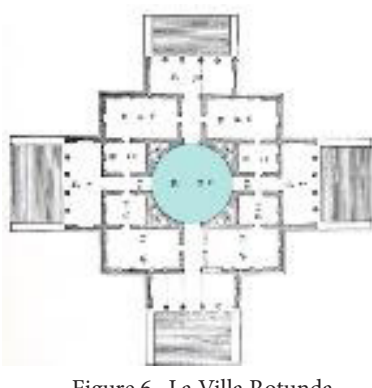

Figure 6. La Villa Rotunda

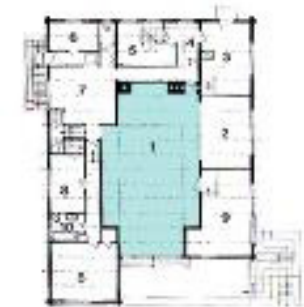

Figure 8. Kuhner villa, Adolf Loos
(Fig $5 \sim 8$. Rabeneck and al., 1974, 87)

\section{2) Condensed/ released type}

Hertzberger shows his conception of flexible space in many of his projects. As an architect who mainly concerned social influence of space and criticized artificial features of modern architecture, he took a resolute attitude to flexible space: a permanent form allowing polyvalent interpretations without its own changing. This idea about function and form initially derived from historic urban structures, and Hertzberger applied the idea to many of his built projects.

As an effort to create polyvalent space, "leaving space" for various interpretations is as important as "making space" to him. In his design it is not difficult to find condensed space for specific purposes such as washing, bathing, stairways, etc.(Fig. $9,10)$ The reasonably located condensed space furnishes with appropriate functions around it. Thus he tried to make minimum functional space (condensed space) within maximum allowance of interpretations (released space). In this way, his design induces multiplicity by evoking form and functions each other. 

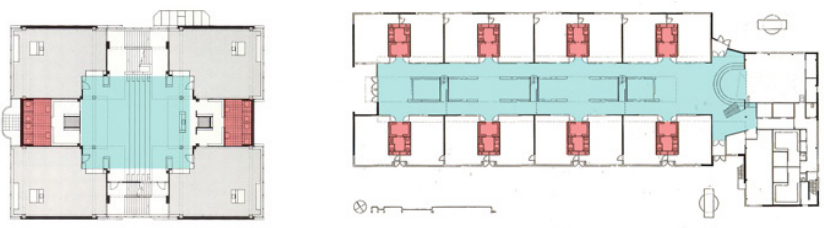

Figure 9. Montessori school at Amsterdam (Left), Hertzberger 1991, 143 Figure 10. De Polygoon Primary school (Right), Hertzberger 2002, 117

3) Non-hierarchical type

The traditional Japanese house shows another type of polyvalence. As the most typical of feudal-period landowner's house Nagatomi House (Fig. 11) is built in the early nineteen century in Ibogawa, Hyogo Prefecture, Japan. In this house there is no hierarchy between rooms. Every room has the same spatial quality, and even there is no designated "circulation." The circulation changes according to different room layout. This kind of flexibility is resulted from relations between rooms.

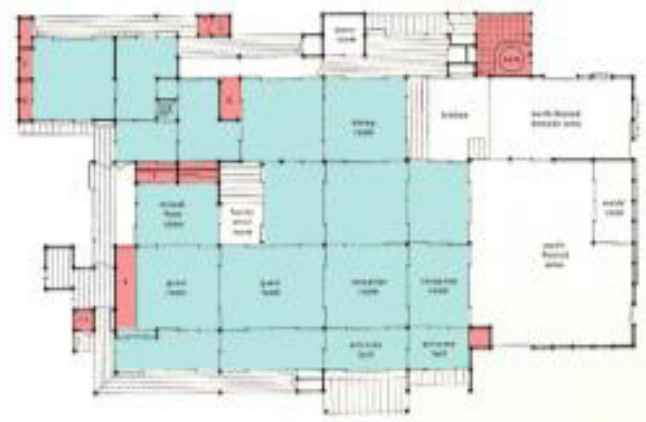

Figure 11. Nagatomi house, Itoh,1967, 100

Some of SANAA's works have the similar feature. Especially in Stadstheater project (Fig. 12), the plan is a rectangle that is subdivided into smaller rectangles of different sizes. There is no obvious hierarchy between rooms, and the plan is almost reduced into some geometrical patterns in accordance with different user scenarios. Though different functions are assigned to the rooms with different sizes, the functions are not permanent. For long narrow rooms are more often used as corridors the long narrow rooms can be corridors, but these are not designated as "corridors."

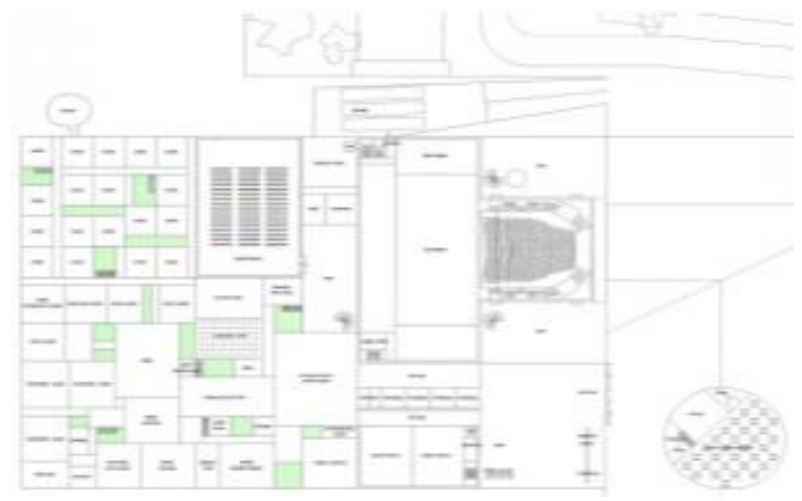

Figure 12. Stadstheater project, Sejima and Nishizawa, 2000, 290

Within non-hierarchical rectangles, according to Sejima, "one can use the rectangles created by subdividing the overall rectangular plan and assign this rectangle the function of a room and that rectangle the function of corridor or a courtyard. Any number of combinations is possible with this plan. That is why it is flexible. A rectangle can be a room at one time and a circulation space at another time."(Aoki, 1999)

Aforementioned precedents of polyvalent forms achieve flexibility from its own adaptable feature. Adaptability, indeed, is another word for flexibility. Unlike multi-functionality, adaptability relies on users' customization to a given space. The adaptable space can be used for any kind of activities as far as the space can afford. However, beyond its capability the adaptable space is no longer flexible. In adaptable space, the variety of possible activities and satisfaction is significantly limited by the given spatial properties which can be size, material and building systems.

\section{HYPOTHESIS: CONTEXTUAL RELATIONS}

Multi-functionality can afford changeable environments with satisfying spatial conditions; however it lacks tolerance to accommodate other uses but intended functions by an architect. Meanwhile, flexibility by polyvalent form relies only on the vague anticipation of an architect with hoping user's broad interpretations, which might be considered as no flexible space in a technical sense. Here lies a contradiction of flexibility in architecture: whether a space adapts to users or users adapt to a space; that is, to what extent architect can control his or her flexible design without infringing users' free interpretations of the space. This contradiction hampers the realization of flexibility in architecture.

Both flexibility by multi-functionality and that by polyvalent form have one thing in common. Both multi-functionality and polyvalence attain architectural flexibility by changing its spatial properties; one is by changing its functions, the other is by changing user's interpretations. The fact that in order for a space to be flexible the space should either be equipped with multi-functions or be adaptable to embrace user's various interpretations causes the contradictory situation. To narrow this discrepancy it is necessary to expand the purview of the object of architectural flexibility.

A building is not a simply agglomerated functions but a synthetic creature with organic relations between spaces defined by users. Quite often the relations between spaces affect the overall use of a building more than the rooms in it do. Simply changing the circulation, which can vary private and public domains, a building may have totally different aspects. This is where my design hypothesis begins. Like a sentence which has a different meaning when the same words are linked with different auxiliary or adverb, a building may have different meaning with changed relations between functions. What if the fidelity of function can be maintained by well-equipped rooms like a well-defined word, while the freely changeable relations between the rooms enable users to interpret the building in a number of different uses? The relation can connect, disconnect, merge, empty, dissolve or sometimes accentuate the adjacent functions. Can this manipulation of individually functional cells yield a flexible form as an integrated organization rather than a simple collection of functions?

I devote the last half of this study to present a design proposition to test this design hypothesis, the Contextual Relations. With all my carefulness, I tried to find a proper site and program to design an architectural flexible form with the Contextual Relations. The 
feasibility of the design, indeed, may not guarantee any resolution of the contradiction. However, I think it is worth considering as another possible story about architectural flexibility.

Table 1. Diagram of the architectural flexibility type

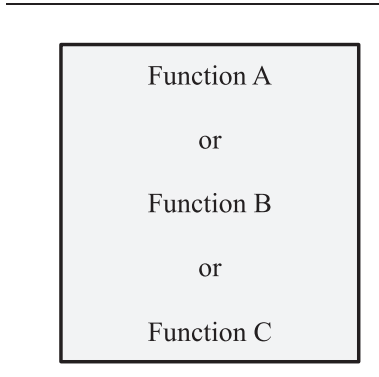

$<$ Multi-Functionality model $>$

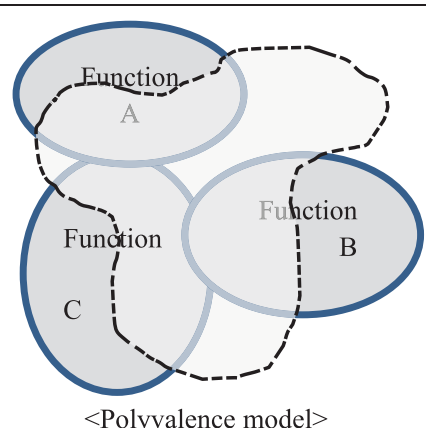

$<$ Polyvalence model $>$

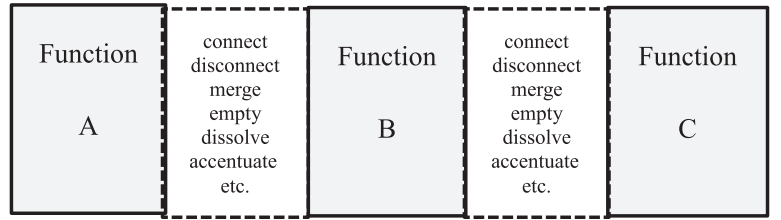

$<$ Contextual Relations model $>$

\section{DESIGN PROPOSITION: COMMUNITY-CENTERED SCHOOL}

\section{(1) Background}

On March 15, 2007, New York state officials added nine city schools to the list of those that are in danger of being shut down. ${ }^{2}$ Junior High School 13(M013) in Harlem, located on the 1573 Madison Avenue, NY, is one of them. Under the existing education segregation problem in Manhattan, this shutting down of a public school in Harlem does not only mean a failure of one institution, but it would result in deterioration of nearby schools by increased overcrowding, which is actually happening in the Brooklyn area. Additionally, considering the fact that the neighborhood schools are used as community spaces in Harlem, the absence of M013 would make the community condition worse.

Social scientist Kenneth B. Clark argued that the reason for chronic academic failure is neither racial inferiority nor cultural deprivation resulted from poor community circumstances. Clark pointed out the inefficiency of urban public school systems as the fundamental reason for the academic failure in many public schools in the ghetto and calls for the change in the educational system and the improvement of teacher attitudes. In the same sense, aware of the limitations of the present urban public school system, Preston Wilcox proposed a new school system: the communitycentered school (Gross and Gross, 1969). Such a school will be managed mainly by the community, with more responsibility for their children's education. The community-centered school would provide an atmosphere promoting intellectual curiosity and responsibility to cultivate its intellectual resource as well as basically

\footnotetext{
2 Herszenhorn, David M. "Eight City Middle Schools Join Those at Risk of Closing.” The New York Times, 16 Mar. 2007
}

perform as an education institution. In addition, as a community center it would become the facility satisfying the community's need for recreation and fun, the place for community policymaking related to health, traffic, housing, etc., the cultural center to express the community's concerns through art, music, drama, etc. and a locus for mutual aid within the community to overcome its financial troubles.

The community will participate in the education of their children against the indifference of the city bureaucracy. In addition, this new type of space for education is not a solution only for the educational crisis in this area but for the urban change of this community. As a new type of urban public space, this flexible space can support the community's various activities which the community needs responding to the change they encounter. The viability which the space will generate reveals the sites value in terms of urban context as a gateway from the other parts of the city Manhattan to the community from the other parts of the city.

\section{(2) Site}

The site is located on the E106th street between Park Avenue and Madison Avenue in Manhattan, NY. In terms of the urban context, interestingly, the area around the site shows a layered feature (Fig.13). First of all, from the west there is the Central Park, which is the largest open public space in Manhattan, and along the Central Park, which is the Museum Mile, there are luxury condominiums

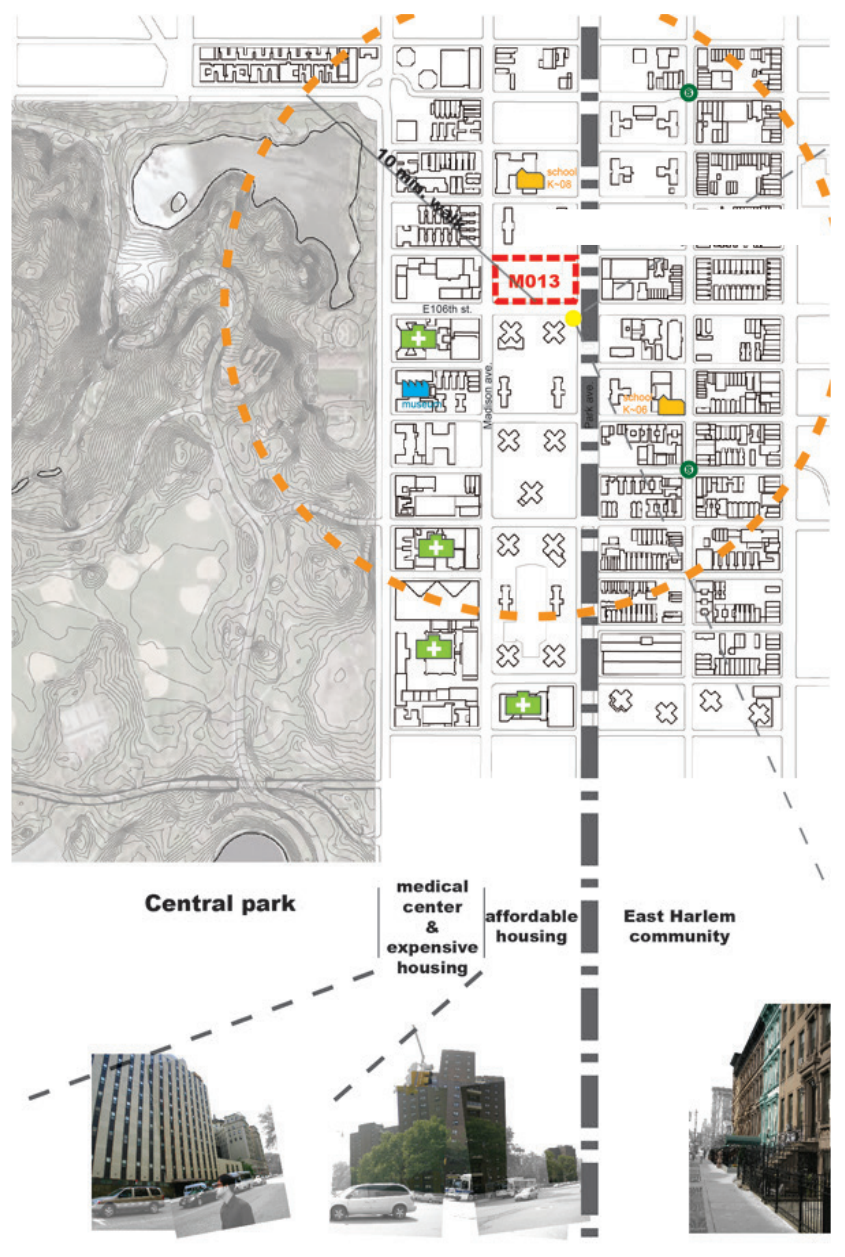

Figure 13. Site condition 
and medical facilities, which is the main medical complex in the Manhattan. Next to it, tower type of housings appears. The public housing blocks are separated from East Harlem community by the elevated railway on the Park Avenue.

(3) Space Layout

Due to the limited location of the under paths through the elevated railway on the Park Avenue, people, mostly from East Harlem community, pass through the E106th Street. This fact affects the shape of the building. The building consists of four bands of functions which have the same direction as the main pedestrian path with emptying the space between the bands (Fig.14). This form of the building creates naturally secured space for the school function in the farthest place from the main street while permitting gradual permeableness, and the linear open spaces create another streetscape when building is fully open to public. According to the design hypothesis, the design begins with clear division of fixed functions and in-between space where various relations happen (Fig.15).

The building performs as two independent institutions. The rooms equipped with proper spatial quality for each assigned function bar are located in the position where relations with neighboring rooms can be anticipated. Fig. 16 shows the interpretation of the traditional school functions into its possible transition based on the similar spatial demands. The functions with the similar spatial properties can be related with more frequency.

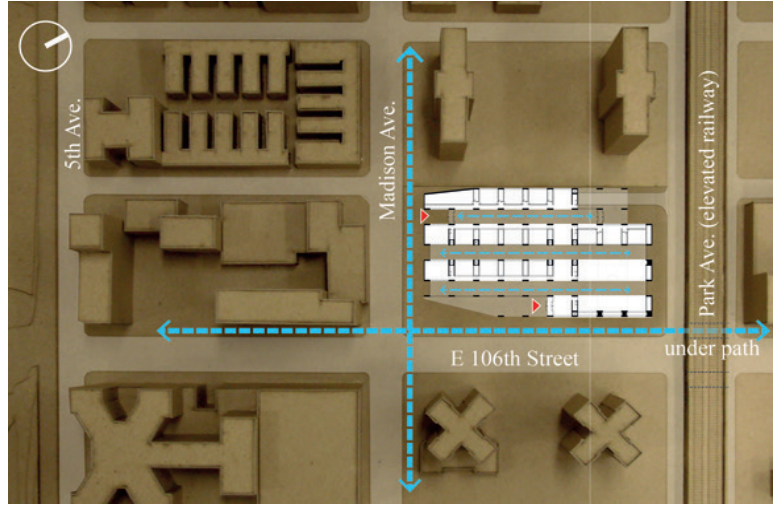

Figure 14. Site plan and main pedestrian path

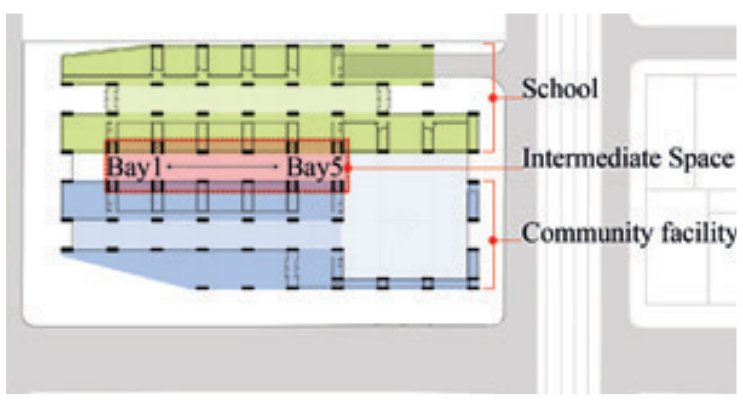

Figure 15. Function-band layout

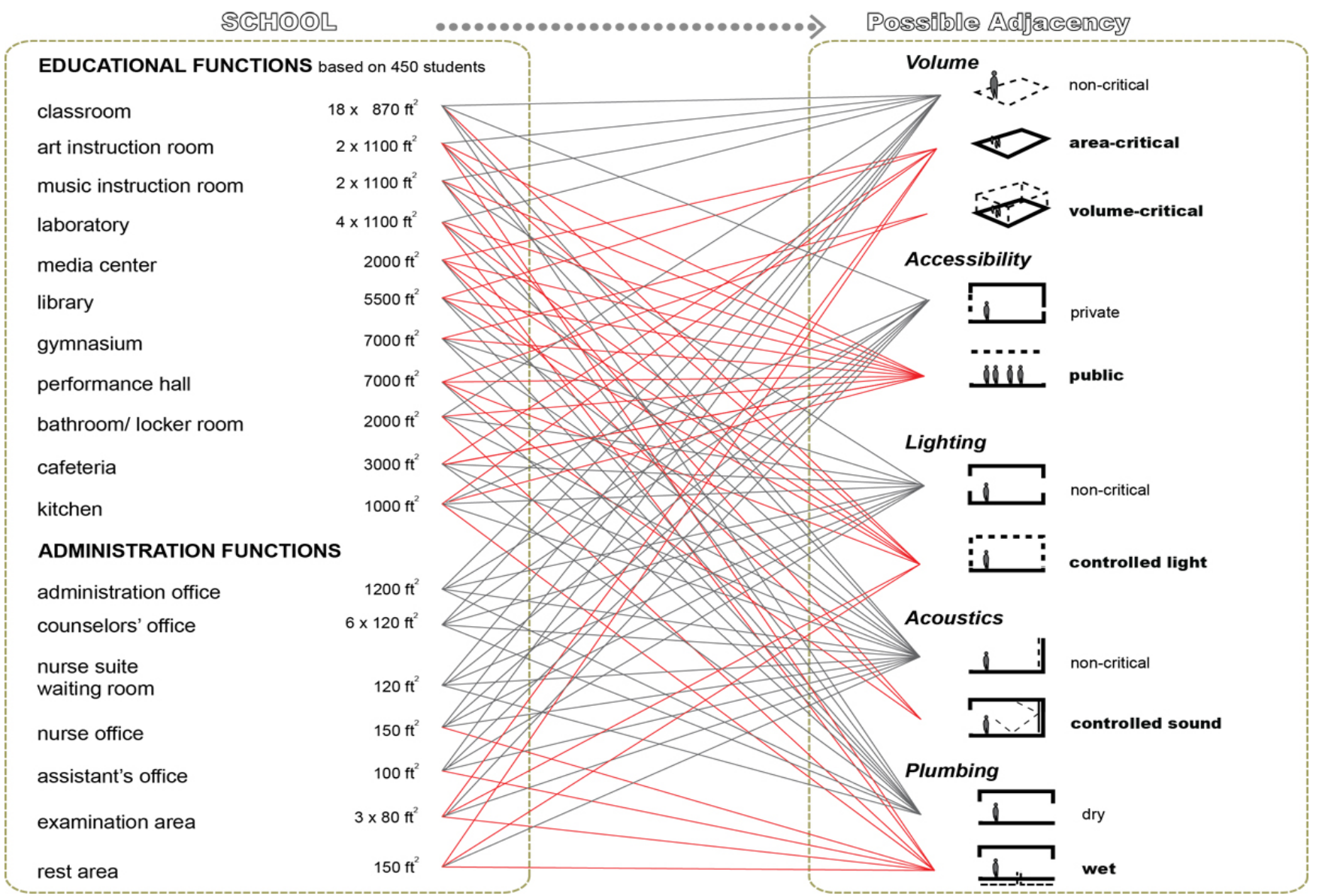

Figure 16. Space attribute chart for possible adjacency of each function 
Thus the functions can be allocated nearby or on the same location in the adjacent bars where relational changes between them can happen. For example, gymnasium, performance hall and media center have the public feature in common, and art instruction room, library and laboratory need controlled light. Those functions are located nearby or on the same location in the each bar (Fig. 17) that the relations change, i.e. connect, disconnect or merge, etc., between the functions can yield possibility to be flexibly used.

The actual relational changes happen in the Intermediate Space shown in Fig. 15 which consists of five bays between the school and the community

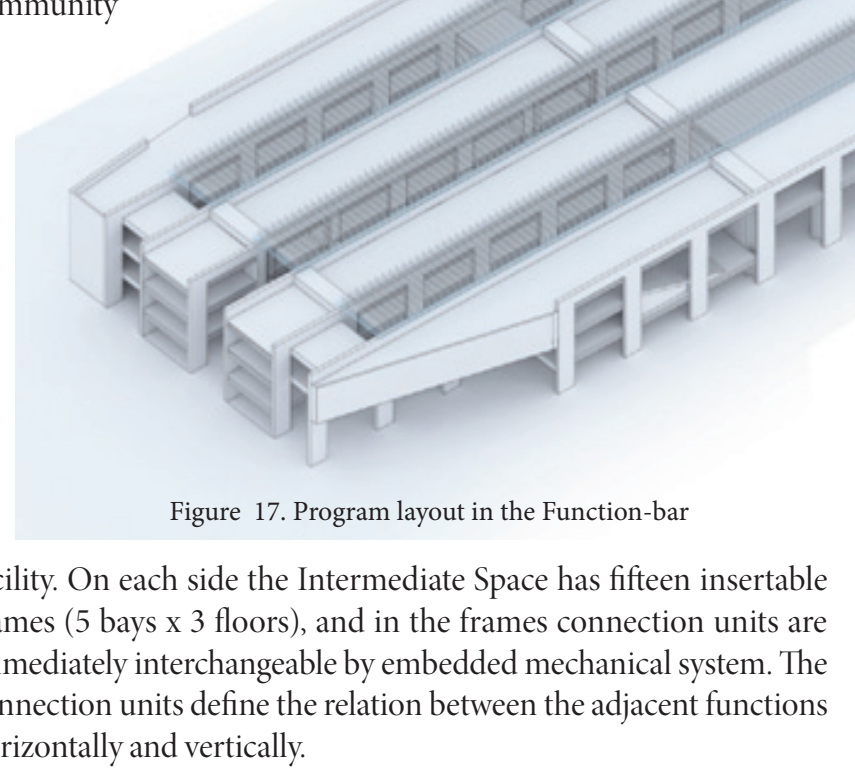

(4) Connection Type

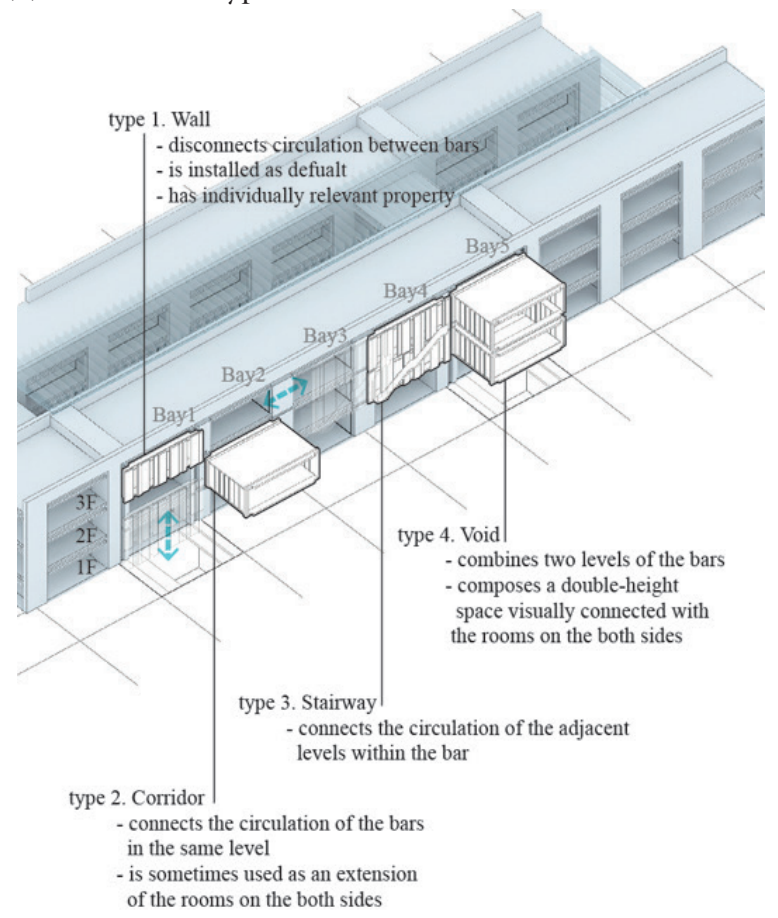

Figure 18. Connection types rames.

ii. Type 2. Corridor - this unit connects the horizontal circulation between the school and the community facility. Often furnished with the continuous properties as the adjacent rooms, this unit can be uses as an extension of the room in the both sides.

iii. Type 3. Stairway - this unit connects the vertical circulation between the rooms in the consecutive levels in the same bar.

iv. Type 4. Void - this unit combines four rooms as a double height space. It provides visual connection while disconnecting circulation on the upper level.

The units are prefabricated and stored on the basement. Through the hatch at the Bay 1 and Bay 5 the units are slid out and moved to the intended positions by mechanical system.

Users choose appropriate connection types for their intention. The immediate responsive way of using space enables users to find the most suitable form for each intention by trial and error. The community will find the most suitable form for weekend and summer vacations after some years' executions. Sometimes for unusual events they enjoy a space by an ad-hoc attempt.

(5) One Possible Usage

The highly responsive environment resulted from the immediate variation of the connection composition yields a number of ways of using this building. Initially, during a day, the building is used for school as a whole, and it serves as a community education facility in the evening with maintaining schools security by disconnecting circulation in some spots. On Sundays community events such as flea market or wedding party can be held on the lower level. Even during summer holidays, which the space can be planned for somewhat longer period, the majority of the building except the minimum space for school's security can be dramatically changed for a certain purpose. The following shows how the building performs based on the simple user plan described above. Of course, it is only small part of thousands of possibilities. 
School

[08:00 18:00 on week days]

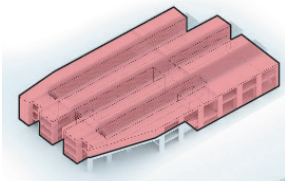

connection makes the building fully accessible by students
Afterschool class

[19:00 24:00 on week days]
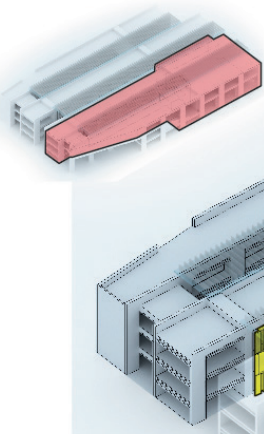

The main school part remains secured while half of the school is open to the community for education purpose.

\begin{tabular}{ccccccc}
\hline floor & & Bay1 & Bay2 & Bay3 & Bay4 & Bay5 \\
\hline \multirow{3}{*}{$\begin{array}{c}\text { School } \\
\text { side }\end{array}$} & 3F & Typ.1 & Typ.1 & Typ.1 & Typ.1 & Typ.2 \\
\cline { 2 - 7 } & 2F & Typ.2 & Typ.1 & Typ.1 & Typ.1 & Typ.2 \\
\cline { 2 - 7 } & 1F & NA & NA & NA & NA & NA \\
\hline \multirow{2}{*}{$\begin{array}{c}\text { Community } \\
\text { side }\end{array}$} & 3F & Typ.1 & Typ.1 & Typ.1 & Typ.1 & Cntd. \\
\cline { 2 - 7 } & 2F & Cntd. & Typ.1 & Typ.1 & Typ.1 & Cntd. \\
\cline { 2 - 7 } & 1F & NA & NA & NA & NA & NA \\
\hline \multicolumn{5}{c}{ (NA: not applied, Cntd.: connected) }
\end{tabular}

\begin{tabular}{ccccccc}
\hline floor & & Bay1 & Bay2 & Bay3 & Bay4 & Bay5 \\
\hline \multirow{2}{*}{$\begin{array}{c}\text { School } \\
\text { side }\end{array}$} & 3F & Typ.1 & Typ.1 & Typ.1 & Typ.1 & Typ.1 \\
\cline { 2 - 7 } & 2F & Typ.1 & Typ.1 & Typ.1 & Typ.1 & Typ.1 \\
\cline { 2 - 7 } & 1F & Typ.1 & Typ.1 & Typ.1 & Typ.1 & Typ.1 \\
\hline \multirow{2}{*}{$\begin{array}{c}\text { Community } \\
\text { side }\end{array}$} & 3F & Typ.1 & Typ.1 & Typ.1 & Typ.1 & Typ.1. \\
\cline { 2 - 7 } & 2F & Typ.1 & Typ.1 & Typ.1 & Typ.1 & Typ.1. \\
\cline { 2 - 7 } & 1F & NA & NA & NA & NA & NA \\
\hline
\end{tabular}
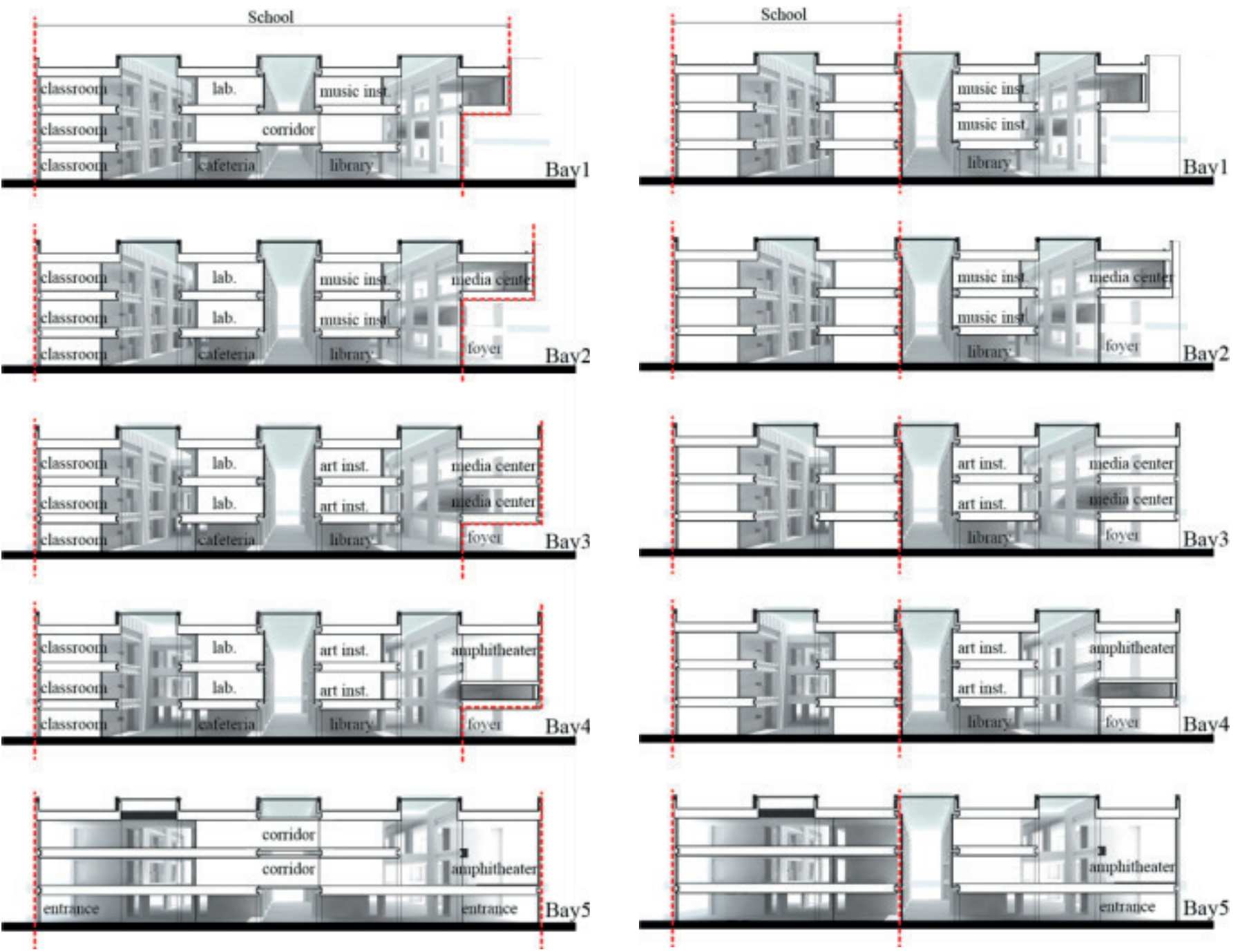
Flea market

[09:00 20:00 on a Sunday]

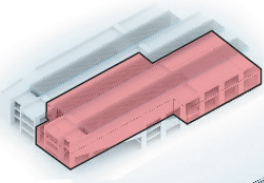

The central coriddor turns into a street, and up to the 2 nd level

is fully open to the public for festive purpose.

\begin{tabular}{ccccccc}
\hline floor & & Bay1 & Bay2 & Bay3 & Bay4 & Bay5 \\
\hline \multirow{2}{*}{$\begin{array}{c}\text { School } \\
\text { side }\end{array}$} & 3F & Typ.1 & Typ.1 & Typ.1 & Typ.1 & Typ.1 \\
\cline { 2 - 6 } & 2F & \multirow{2}{*}{ Typ.3 } & NA & NA & NA & \multirow{2}{*}{ Typ.3 } \\
\cline { 2 - 6 } & 1F & & NA & NA & NA & \\
\hline \multirow{2}{*}{$\begin{array}{c}\text { Community } \\
\text { side }\end{array}$} & 3F & Typ.1 & Typ.1 & Typ.1 & Typ.1 & Typ.1. \\
\cline { 2 - 6 } & 2F & \multirow{2}{*}{ Typ.3 } & NA & NA & NA & \multirow{2}{*}{ Typ.3 } \\
\cline { 2 - 4 } & & & NA & NA & NA & \\
\hline & & & & & (NA: not applied)
\end{tabular}
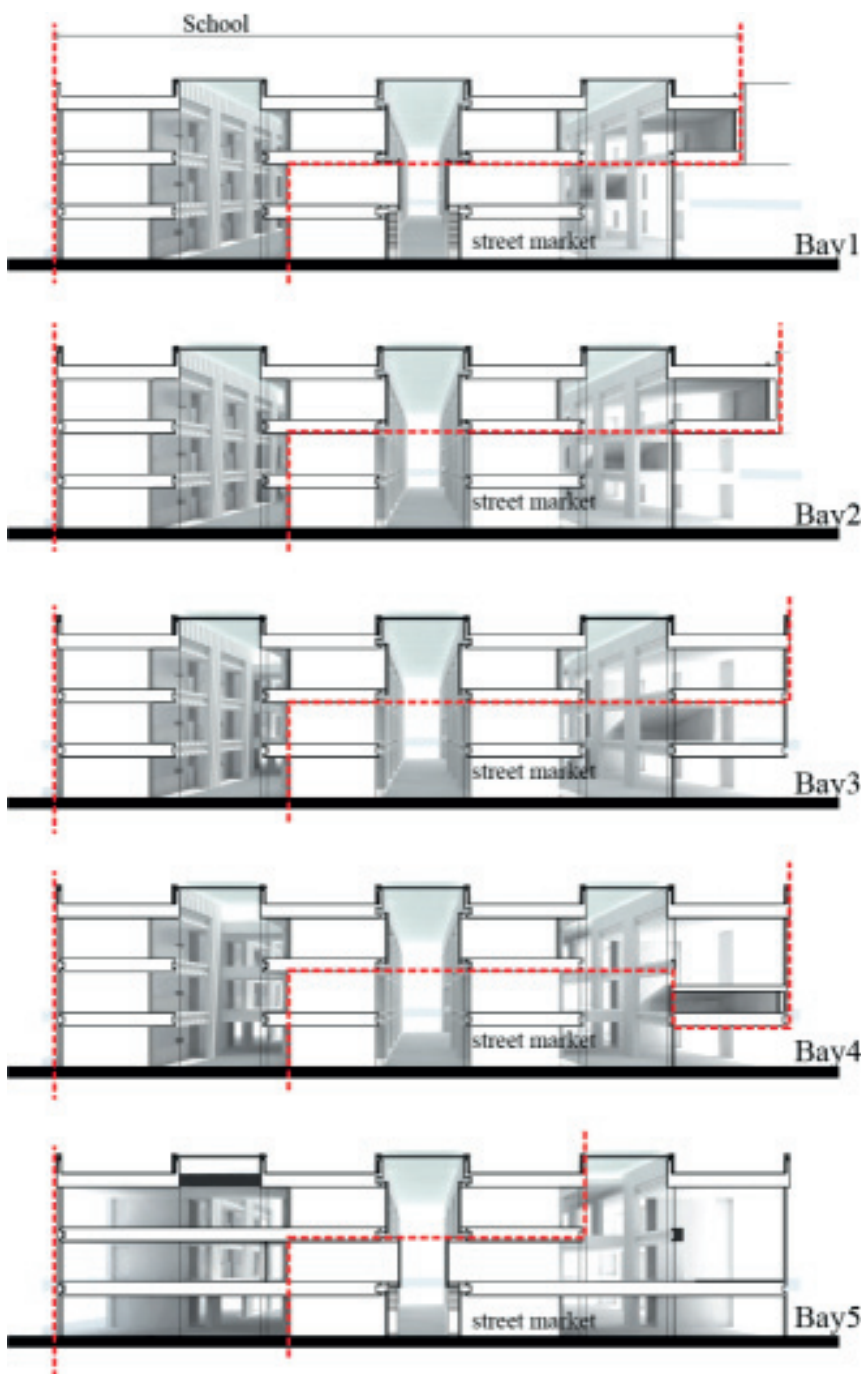

Artist residency

[during summer holidays]

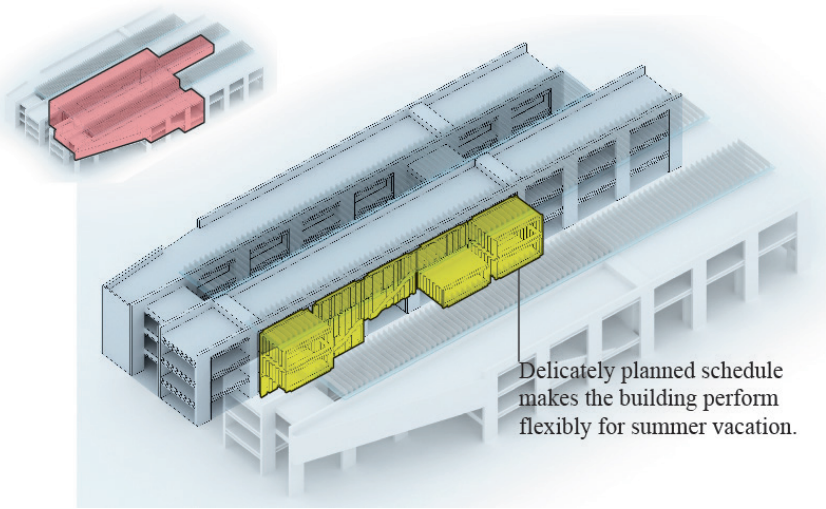

\begin{tabular}{|c|c|c|c|c|c|c|}
\hline floor & & Bay1 & Bay2 & Bay3 & Bay4 & Bay5 \\
\hline \multirow{3}{*}{$\begin{array}{l}\text { School } \\
\text { side }\end{array}$} & $3 \mathrm{~F}$ & \multirow{2}{*}{ Typ.4 } & Typ. 1 & \multirow{2}{*}{ Typ.3 } & Typ.1 & \multirow{2}{*}{ Typ.4 } \\
\hline & $2 \mathrm{~F}$ & & \multirow{2}{*}{ Тур.3 } & & Typ. 2 & \\
\hline & $1 \mathrm{~F}$ & Typ.1 & & NA & NA & NA \\
\hline \multirow{3}{*}{$\begin{array}{c}\text { Community } \\
\text { side }\end{array}$} & $3 \mathrm{~F}$ & \multirow{2}{*}{ Cntd. } & Typ.1 & \multirow{2}{*}{ Typ.3 } & Typ.1 & \multirow{2}{*}{ Cntd. } \\
\hline & $2 \mathrm{~F}$ & & Typ. 1 & & Cntd. & \\
\hline & $1 \mathrm{~F}$ & Typ.1 & Typ.1 & Typ.1 & Typ.1 & NA \\
\hline
\end{tabular}
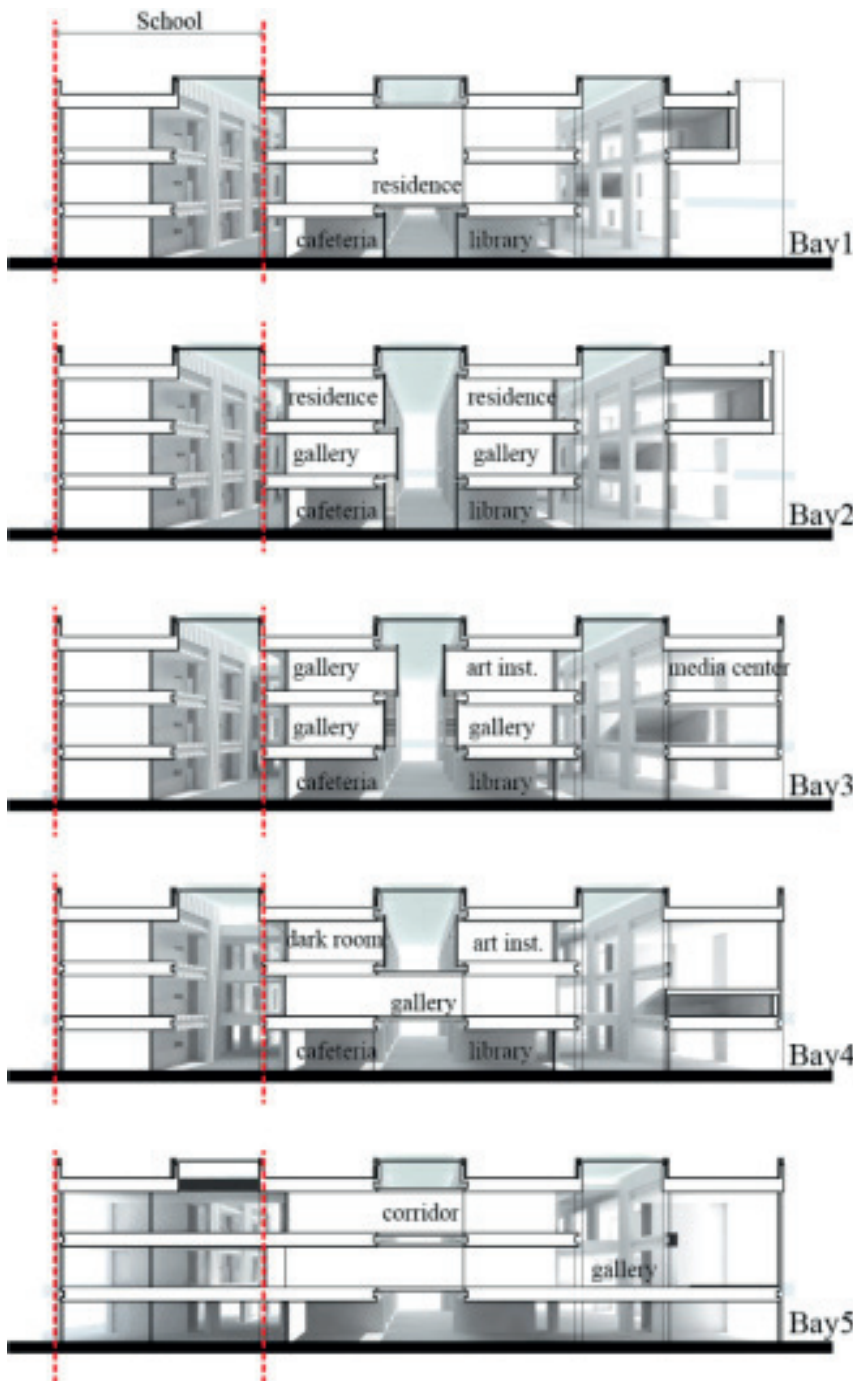


\section{CONCLUSION}

Thus far the conception of flexibility in architecture is explored focused on the intrinsic contradiction, which is interpreted in two different viewpoints; provider's and user's. Simply providing a big, open space and letting users to use the space flexibly is the most common mistake in designing flexible space for the insufficient spatial properties to support the required functions. On the other hand, providing given number of intended functions can hamper the possibility of "other unexpected" uses.

Confined with functions within given space, it is hard to narrow the discrepancy. Thus, in this study, to attain spatial flexibility I suggest to expand the purview of the object of the flexibility beyond functional unit; which is the relations between functions. The proposed system which consists of well-equipped functions linked immediately changeable relations is an alternative model for flexibility in architecture neither by changing functions of a space nor by various users' interpretation.

In the modern movement era, flexibility was an issue related with the dynamically changing society. Recently, the practical value of architectural flexibility is underscored on the sustainability as well. From the urban fabric to a small room flexible usage can bring up the effective way of using our limited resources. I would appreciate further arguments on flexibility in architecture, and hope that various ways of utilizing and designing space for flexible use resolving practically individual conditions are proposed rather than providing a big white cube space under the motto of "overprovision first and division later."

\section{REFERENCE}

Aoki, Jun. (1999) The Flexibility of Kazuo Sejima. Japan Architect, vol.35, Autumn, 6-7

Collins, Peter.(1965) Changing Ideals in Modern Architecture 1750 1950. Montreal: McGill University Press.

Forty, Adrian.(2000) Words and Buildings: A Vocabulary of Modern Architecture. New York, NY: Thames \& Hudson Inc.

Gropius, Walter.(1954) Eight Steps Toward A Solid Architecture. Architectural Forum, Feb.

Gross, Beatrice and Gross, Ronald.(1969) Radical School Reform.. New York, NY: Simon and Schuster.

Hertzberger, Herman.(1991) Lessons for students in architecture. Rotterdam: Uitgeverij 010.

Hertzberger, Herman.(2002) Articulations. Munich. Berlin. London. New York: Prestel.

Itoh, Teiji.(1967) The Essential Japanese House: Craftmanship, Function, and Style in Town and Country. Tokyo: John Weatherhill, INC., New York and London: Harper \& Row, Publisher, INC.

Koolhaas, Rem.(1995) Last Apples. S,M,L,XL. New York, NY: The Monacelli Press.

Lefebvre, Henri.(1991) The production of space. Cambridge, MA: Blackwell.

Lobsinger, Mary L.(2000) Cedric Price: An Architecture of the Performance. Daidalos, Jan., 22-29.

Mathews, Stanley.(2006) The Fun Palace as Virtual Architecture : Cedric Price and the Practices of Indeterminacy. Journal of Architectural Education, 39-48.
Rabeneck, Andrew, David Sheppard, and Peter Town.(1973) Flexible(?) housing. Architectural Design, Nov., 698-732.

Rabeneck, Andrew, David Sheppard, and Peter Town.(1974) Flexibility/ Adaptability. Architectural Design, Feb., 76-90.

Rogers, Richard.(1998) Cities for a small planet. Westview Press.

Rossi, Aldo.(1982) The Architecture of the City. Cambridge, MA: The MIT Press.

Sarah W. Goldhagen and Réjean Lagault (2000) Anxious Modernisms. Cambridge, MA: The MIT Press

Sejima, Kazuo. And Nishizawa, Ryu.(2000) Kazuo Sejima + Ryu Nishizawa. Madrid: El Croquis 77+99.

(Received September 9, 2013/Accepted December 26, 2013) 